\title{
Personal and Social Tipping Norms: Race and Sex Differences
}

\author{
Jeremy E. Whaley ${ }^{1} \&$ Wanda M. Costen ${ }^{2}$ \\ ${ }^{1}$ Department of Retail, Hospitality, and Tourism Management, University of Tennessee, Knoxville, Tennessee, \\ USA \\ ${ }^{2}$ School of Business, MacEwan University, Edmonton, AB, Canada \\ Correspondence: Jeremy E. Whaley, Department of Retail, Hospitality, and Tourism Management, University of \\ Tennessee, Knoxville, TN, United States. E-mail: jwhale15@utk.edu
}

Received: June 3, 2019 Accepted: July 2, 2019 Online Published: July 12, 2019

doi:10.5539/ijms.v11n3p1 URL: https://doi.org/10.5539/ijms.v11n3p1

\begin{abstract}
Tipping is both a personal and social norm, which can also vary according to the consumer's racial background and sex. This study investigated the extent to which restaurant guests' personal and social tipping norms vary based on race (White vs. Africa American) and sex. The researchers used a consumer panel comprised of 623 participants in 2016. A two-by-two ANOVA was conducted to examine race and sex effects on personal and social tipping norms. The results demonstrated both main and interaction effects of race and sex in personal and social tipping norms. Based on the results, the researchers discuss implications for scholars, restaurant owners, and managers.
\end{abstract}

Keywords: personal norm, social norm, tipping, race, sex

\section{Introduction}

\subsection{Restaurant Tipping}

Tipping is a standard practice to which many restaurant guests adhere by leaving money for restaurant servers after their service experience. Although a significant stream of research on the topic suggests that the service received motivates guests to tip (Conlin, Lynn, \& O’Donoghue, 2003; Lynn, 2006a; Lynn, 2009; Lynn \& Sturman, 2010; Whaley, Douglas, \& O'Neill, 2014), a growing body of literature indicates that tipping is a commonly-practiced social norm regardless of the quality of service received (Azar, 2010; Whaley, 2011; Whaley et al., 2014). Interestingly, Koku (2005) proposed that tipping in restaurants differs from tipping in other service encounters outside the restaurant industry. Moreover, Koku (2005) claimed that the norms of restaurant tipping might signal a guest's appreciation for previously received services.

Given that restaurant tipping is a social obligation or construct, this research proposed that tipping is a case both of personal and social norms. Azar (2007b) posits that tipping is personal in the sense that consumers give servers money, although they are not legally obliged to do so. However, if the restaurant or service provider includes a gratuity (i.e., tip) in the guest's check as a request to receive its services, then the tip must be paid. Tipping is social in the sense that tipping is expected and sometimes required, in most restaurant settings to avoid feelings of regret, shame, or even guilt (Azar, 2004). Researchers have found that feelings of obligation, regret, and concern for one's self-esteem motivate consumers to engage in restaurant tipping (Azar, 2007a; Azar; 2010, Whaley et al., 2014).

Simultaneous production and consumption are key contributors to the service exchange from which the provider cannot separate him/herself (Parasuraman, Zeithaml, \& Berry, 1985). Further, the way a service provider delivers the service is more critical than the kind of service s/he provides (Parasuraman, Zeithaml, \& Berry, 1988). Therefore, interactive bond forms between the service provider and the customer. The academic literature on restaurant tipping is vast and well-developed: including motivational factors previously studied, such as the service received (Lynn \& Grassman, 1990); the social obligation to tip restaurant servers (Azar, 2010), and the ambient conditions' effect on tipping behavior (Whaley, Kim, \& Kim, 2019). There are no clear findings on the relationship between tipping and the service received. Tipping is poorly-related (Lee, 2015), unrelated (Lee, 2015), or positively-correlated with the service received (Whaley et al., 2014). The personal connection that the server forms with guests during the restaurant experience is a crucial motivator in consumers' willingness to return and engage in post-consumption behaviors (Whaley, Lee, \& Kim, 2019). 
Restaurant service requires service workers to be gregarious and engaging; however, as with all products and services, restaurant guests differ in preferences, and in many cases, consumer tipping behavior differs by race (Brewster \& Nowak III, 2018). Further, researchers have posited that tipping behavior can change based on the guest's sex, and that of the restaurant server (Whaley, 2011; Whaley et al., 2014). For example, Koku (2005) found that gender made a little difference in tipping behavior in restaurants, but not in-service encounters outside the restaurant industry. Thus, it is both timely and necessary that scholars re-examine restaurant guests' tipping behavior, most especially the effects of race and sex interactions or preferences during the dining experience. This exploration is particularly important because consumer preferences change constantly.

To this end, the concept of habitus may shed light on both racial and sex preferences and behaviors in a social context. Habitus helps explain sociological experiences by examining social structures, and the particular behavior patterns that groups exhibit as free agents when they come into contact with these social structures (Grenfell, 2014) Thus, habitus entails examining a behavior within a certain context with certain actors, with respect to both their responses as a group and as individuals (Grenfell, 2014). With respect to consumer tipping behavior based on racial motives, habitus implies that groups, or subgroups of individuals, will behave in the same way based upon past and present social structures when interacting with others (e.g., "actors" such as restaurant servers).

Tipping is both a social construct and socially-imposed obligation (Azar, 2010). The current literature remains limited in determining whether restaurant tipping is a personal choice, a norm, or a socially-imposed norm, and the extent to which these norms affect racial tipping behavior. Accordingly, this study examined sex and racial differences in tipping norms that consist of both a personal and social norm. The findings offer researchers new perspectives from which to understand race and sex's main and interaction effects on consumer tipping behavior. Discussion and implications provide specific information on how restaurant owners and managers can better serve their guests based on race and sex.

\subsection{Conceptual Framework}

Consumer patterns of tipping behavior continue to change and evolve, and restaurant guests may choose a restaurant experience based on a personal norm or a socially-imposed norm, whether they are dining alone or with others out of obligation to be apart of a group.

\subsubsection{Personal Norms}

According to Berenguer (2010), personal norms are "internalized rules of conduct that are socially learned vary among individuals within the same society and direct behavior in a particular situation" (p. 111). In contrast to social norms, personal norms relate to preferences caused by one's internal disposition (Kallgren, Reno, \& Cialdini, 2000), in which one's judgment, rather than others' influence, affects behavior (Doran \& Larsen, 2016).

Azar (2007a) argued that guests who engage in poor tipping behavior might feel guilty if they do not tip when a server has tried to connect with them during the dining experience. The argument suggests an individual's moral beliefs may influence h/her norms (Han et al., 2019). Mulinari, Guest, and Isaksson (2019) argued that tipping represents a type of moral economy in which guests feel empathy for the server, or are concerned to do the right thing, by leaving him/her a tip. As such, it can be postulated that restaurant guests' guilt might affect their moral code, and ultimately, their tipping behavior.

While the tipping literature reveals that personal preferences influence tipping norms, interpersonal preferences for restaurant servers have been found to motivate consumer tipping behavior as well (Azar, 2007a). For example, Conlin et al. (2003) reported that the server's friendliness was a key characteristic of servers who received a substantial number of tips. Additionally, a sex-specific (i.e., females) touch on male consumers' hands, while returning the change, motivated male consumers to tip more than when the female server did not touch the male consumer (Stephen \& Zweigenhaft, 1986). Indeed, servers who display a positive response while engaging in reciprocal interactions invoke gratitude and appreciation for their efforts (Fehr \& Falk, 2002; Teng \& Cheng, 2013). In this study, personal norms related to tipping deal directly with a personal connection with the server, sex preferences, and the service received.

\subsubsection{Social Norms}

Tipping in the United States is a common practice and social norm (Azar, 2010). Kim and Kim (2019) believe that social norms have a significant effect when individuals observe each other during the act of giving. In the context of restaurants, Whaley, Lee, and Kim (2019) suggest that consumer compliance with the social norm of tipping influences selecting the same server on future visits.

While personal norms require introspection, social norms require the observation of a specific behavior by others (Elster, 2007; Schram \& Charness, 2015). Many researchers have studied the social characteristics of the tipping 
behavior between guests and servers (Azar, 2007a; Brewster \& Mallison, 2009). According to Azar (2010), $84.7 \%$ of survey respondents tipped to conform to the social norm. When a guest complies with social norms by leaving a flat dollar tip, or percentage tip, his/her emotions may not be congruent with the practice of tipping in that guests may feel negative feelings due to the receipt of poor service, but leave a tip regardless of the server's poor efforts. Social norm theory implies that restaurant guests may experience negative feelings such as shame, regret, or the fear of being judged by others (Azar, 2004). That is, if consumers consider not leaving a tip for the server after a dissatisfying experience, then they may experience the previously mentioned emotions (Azar, 2004). In this study, social norm refers to the pressure to tip, the obligation to tip when dining with family or friends, and the obligation to tip, even when service is bad.

\subsubsection{Racial Differences in Norms}

Tip amounts and the service received at restaurants may depend on a guest's race. Lynn and colleagues found that African-Americans tip differently than Whites, but the motives were inconsistent across a variety of different studies; for example, some studies found that African-Americans are unfamiliar with the norm of tipping restaurant servers (Lynn, 2000; Lynn, 2004a, 2004b; Lynn, 2006a; Lynn \& Thomas-Haysbert, 2003). Other researchers have claimed that a majority of servers believe that African-Americans are poor tippers, and consequently, servers provide them poorer service (Banks et al., 2018; Lynn \& Thomas-Haysbert, 2003). Lynn (2000) administered a survey and found that restaurant servers perceived that African-Americans (94\%), Hispanics (70\%), and Asians (27\%) were poor tippers.

In contrast, none of the restaurant servers who participated in the survey claimed that Whites were poor tippers (Lynn, 2000). Similarly, Lynn and Thomas-Haysbert (2003) examined the differences between African-American and White groups using a phone survey $(n=1,837)$ and found that African-Americans' patterns of tipping less than Whites was attributable to price sensitivity (i.e., disposable income). Brewster and Nowak III's (2018) recent study also indicated that African-American consumers tip less than White consumers, but the magnitude of the tip differed by a small margin of 3.5\%. The authors argued that African-American guests might be unaware of the injunctive norm (e.g., fifteen to twenty percent) and descriptive tipping norms. Lynn and Brewster (2015) explained that a descriptive norm is one that specifies the way an individual is expected to behave, while an injunctive norm is specific to one's "attitudes or behaviors that are perceived to be acceptable, expected correct, or otherwise socially approved” (Lynn \& Brewster, 2015, p. 69).

Other researchers have reported that African-Americans do not practice the social norm of tipping for a variety of reasons. These include a lack of awareness of the social norm percentages, or being from single-family homes without disposable income (Lynn \& Thomas-Haysbert, 2003). Also, service providers' racial prejudices against African-Americans motivate African-Americans to tip differently than others (Dirks \& Rice, 2004a; Dirks \& Rice, 2004b). These findings infer that tipping is a habitual behavior, or a social structure, that reflects the individual's history, and is composed of the set of internal dispositions referred to as habitus (de Morais Sato et al., 2014).

In Banks et al.'s (2018) study, ethnic minority servers reported that their tips are more often below the standard tipping norm. Their result supported many previous findings that restaurant guests' implicit attitudes about a server's sex or ethnicity affect tipping behavior (Ayres, Vars, \& Zakariya, 2005; Brewster \& Lynn, 2014; Lynn et al., 2008). For example, Ayres et al. (2005) found racial disparities in tipping taxi cab drivers in Connecticut. White cab drivers were tipped one-third more than African-American cab drivers, but African-American cab drivers believed that African-American passengers would tip them approximately $58 \%$ less of the time than would White passengers. Brewster and Lynn (2014) also found that when such variables as age, gender, education, and income were controlled, African-Americans tipped 2\% less than Whites and Hispanics. In another example, Lynn et al. (2008) found that White and African American servers' tip percentages differed when guests rated the service received as less than perfect to perfect. White servers' tips increased from $16.8 \%$, when service was less than perfect, to $23.4 \%$ when it was rated as perfect, while African-American servers received $16.6 \%$ of the bill both when service was less than perfect or perfect (Lynn et al., 2008).

Banks et al. (2018) suggested that if ethnic minority servers feel that restaurant guests display conscious or unconscious biases during the dining experience, then the servers may deliver less than desirable service. This scenario creates a self-fulling prophecy in which ethnic minority servers, who deliver poor service to the guests, receive tips less than the traditional norm (e.g., fifteen to twenty percent, Banks et al., 2018). While specific instances indeed exist in which servers attempt to influence guests' tipping behaviors by providing quality service, some guests may tip marginally or nothing at all. Lynn (2006a) provided a variety of reasons why African-Americans do not follow the normed percentages that other consumers do. In summary, ethnic 
minorities may tip less for reasons such as experiencing discriminatory service, having households comprised of lower income-earning families, and being less familiar with and committed to the fifteen to twenty percent tipping norms (Lynn, 2003; Lynn, 2006a, 2006b).

\subsubsection{Sex Differences in Norms}

The literature on sex differences in tipping is limited. However, research in sociology and consumer behavior has suggested that the two sexes differ significantly, and certainly, tip differently. Researchers have reported that male guests typically tip more when dining alone than female guests (Maynard \& Mupandawana, 2009; Parrett, 2006; Lynn, 2006b). On the other hand, studies also have suggested that hairstylists' female clients tend to tip more than their male counterparts (Schwer \& Daneshvary, 2000).

Trivedi and Teichert (2019) found that normally, women are influenced more than men by a smiling model in advertisements. The authors claimed that women might be influenced to a greater extent by a restaurant server's emotional affect (e.g., warm and kind servers). Research has also revealed that females rely more on others than their male counterparts. Specifically, females strive to establish connections with others more than males do, because they focus on developing relationships and want to have pleasant interactions with others (Baumeister \& Sommer, 1997; Cross \& Madson, 1997; Ndubisi, 2006). Further, women are more empathetic than men, as they are willing to help others in need (Mestre, Samper, Frias, \& Tur, 2009). These findings suggest that female consumers tend to exhibit loyalty toward a group of individuals, and thus, they may feel more obligated to tip when they are with friends or family members.

\subsection{Research Objectives}

Based on the literature discussed above, it appears that race and sex influence tipping norms. Therefore, this study addressed the main effects of race and sex on personal and social tipping norms. Although the literature does not suggest that race and sex interact with tipping norms, we examined these two variables' effects on personal and social norms. Thus, the study had the following three objectives:

1) To examine whether race has a main effect on personal and social tipping norms.

2) To examine whether sex has a main effect on personal and social tipping norms.

3) To examine whether race and sex have interactive effects on personal and social tipping norms.

\section{Method}

\subsection{Sample and Data Collection}

The questionnaire was developed with Qualtrics in the springtime of 2016 and distributed to an online consumer panel recruited via eRewards, an online market research firm. The survey contained questions about respondents' current tipping practices (e.g., "Do you tip when dining out?" and "How much do you tip when dining out?"), tipping norms, and demographic information. Of a total of 892 surveys collected, we analyzed surveys of 623 respondents, who constituted the two largest racial groups: White $(\mathrm{n}=381)$ and African-American $(\mathrm{n}=242)$. Table 1 provides the respondents' demographic profiles. The majority of the respondents $(98.1 \%)$ tipped when dining out. The greatest percentage of respondents tipped $15 \%(36.5 \%)$, followed by $20 \%(32.2 \%)$, and $10 \%(12.1 \%)$. 
Table 1. Demographic characteristics

\begin{tabular}{|c|c|c|c|}
\hline & $\underline{\text { Level }}$ & $\underline{\mathrm{n}}$ & $\underline{\%}$ \\
\hline \multirow[t]{2}{*}{ Sex } & Male & 289 & 46.4 \\
\hline & Female & 334 & 53.6 \\
\hline \multirow[t]{2}{*}{ Race } & White & 381 & 61.2 \\
\hline & African-American & 242 & 38.8 \\
\hline \multirow[t]{6}{*}{ Age } & $18-25$ & 51 & 9.0 \\
\hline & $26-35$ & 145 & 25.6 \\
\hline & $36-45$ & 169 & 29.9 \\
\hline & $46-55$ & 115 & 20.3 \\
\hline & $56-65$ & 86 & 15.2 \\
\hline & 66 or older & 51 & 9.0 \\
\hline \multirow[t]{6}{*}{ Employment } & Not employed & 65 & 10.4 \\
\hline & Retired & 102 & 16.4 \\
\hline & Full-time & 319 & 51.2 \\
\hline & Part-time & 69 & 11.1 \\
\hline & Self-employed & 27 & 4.3 \\
\hline & Other & 36 & 5.8 \\
\hline \multirow[t]{8}{*}{ Income } & Less than $\$ 12,000$ & 49 & 7.9 \\
\hline & $\$ 12,000 \sim \$ 20,999$ & 44 & 7.1 \\
\hline & $\$ 21,000 \sim \$ 40,999$ & 139 & 24.1 \\
\hline & $\$ 41,000 \sim \$ 52,999$ & 67 & 11.6 \\
\hline & $\$ 53,000 \sim \$ 67,999$ & 75 & 13.0 \\
\hline & $\$ 68,000 \sim \$ 111,999$ & 122 & 21.1 \\
\hline & $\$ 112,000 \sim \$ 156,999$ & 46 & 8.0 \\
\hline & $\$ 157,000$ or more & 34 & 5.9 \\
\hline
\end{tabular}

\subsection{Measures}

Personal and social tipping norms were the study's main constructs. Because no scale items of personal and social norms were found in the literature, we derived relevant items from the literature. We performed content analysis to categorize the items into personal and social tipping norms. We used established measures from Whaley (2011) and Whaley et al. (2014) and solicited experts' $(n=3)$ opinions to modify and categorize items like personal and social tipping norms.

\section{Analysis}

A two-way ANOVA was performed with the main effects of the race (White and African-American) and sex (male and female). Table 2 presents the ANOVA results, and Table 3 shows the means of the personal and social norms for the two racial groups and sexes. As shown in Table 2, the ANOVA demonstrated race's main effects on server sex $\left(\mathrm{F}_{\mathrm{df}}=14.160, p<.001\right)$, and tipping obligation when with family/friends $\left(\mathrm{F}_{\mathrm{df}}=10.548, p<.001\right)$. Similarly, there were main effects of sex based on the sex of the server $\left(\mathrm{F}_{\mathrm{df}}=24.015, p<.001\right)$, and tipping obligation when with family/friends $\left(\mathrm{F}_{\mathrm{df}}=6.430, p<.05\right)$. These findings suggest that a server's sex influenced African-American and male consumers' tipping behavior more than that of White and female consumers. Further, African-American and male consumers felt more obligated to tip, when dining with friends and family than did White male counterparts.

Table 2. General linear model result: F-statistic

\begin{tabular}{llll}
\hline & $\underline{\text { Race }}$ & $\underline{\text { Sex }}$ & $\underline{\underline{\text { Race } x}}$ \\
\hline Personal Norm & & & \\
When a server established a personal connection, it influences my tipping. & .81 & .95 & .02 \\
A server's gender influences my tipping behavior. & $14.16^{* * *}$ & $24.02^{* * *}$ & $4.90^{*}$ \\
My tipping behavior is directly related to the service received. & .03 & .19 & .002 \\
Social Norm & & & \\
Sometimes I feel pressured to tip. & .06 & .46 & $6.41^{* *}$ \\
I feel more obligated to tip when dining with friends and/or family. & $10.55^{* * *}$ & $6.43^{*}$ & 2.51 \\
I feel obligated to tip even when service is bad. & 2.45 & .84 & .44 \\
\hline
\end{tabular}

Note. ${ }^{*} p<.5,{ }^{* *} p<.01,{ }^{* * * *} p<.001$. 
Table 3. Means

\begin{tabular}{lllll}
\hline & \multicolumn{2}{l}{ White } & \multicolumn{2}{l}{ African American } \\
\cline { 2 - 5 } & $\begin{array}{l}\text { Male } \\
(\mathrm{n}=157)\end{array}$ & $\begin{array}{l}\text { Female } \\
(\mathrm{n}=224)\end{array}$ & $\begin{array}{l}\text { Male } \\
(\mathrm{n}=132)\end{array}$ & $\begin{array}{l}\text { Female } \\
(\mathrm{n}=110)\end{array}$ \\
\hline Personal Norm & & & & \\
When a server established a personal connection, it influences my tipping. & 3.01 & 3.08 & 3.08 & 3.13 \\
A server's gender influences my tipping behavior. & 1.76 & 1.51 & 2.23 & 1.66 \\
My tipping behavior is directly related to the service received. & 3.29 & 3.32 & 3.28 & 3.31 \\
Social Norm & & & & \\
Sometimes I feel pressured to tip. & 2.13 & 2.28 & 2.31 & 2.06 \\
I feel more obligated to tip when dining with friends and/or family. & 2.11 & 2.05 & 2.45 & 2.16 \\
I feel obligated to tip even when service is bad. & 2.34 & 2.45 & 2.27 & 2.29 \\
\hline
\end{tabular}

Finally, these two variables (race and sex) had interaction effects on the sex of the server $\left(\mathrm{F}_{\mathrm{df}}=4.901, p<.05\right)$ and tipping pressure $\left(\mathrm{F}_{\mathrm{df}}=6.413, p<.01\right)$, as shown in Figures 1 and 2, respectively. Specifically, server sex was much more likely to influence African-American male consumers' tipping, while this difference was not apparent among White consumers. Further, African-American male consumers felt more pressure to tip than did their female counterparts, while this pressure was greater for White females than male consumers.

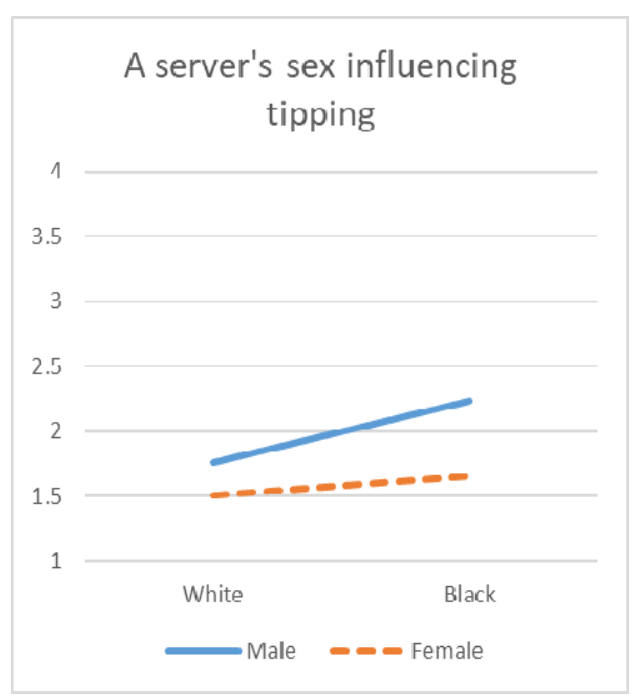

Figure 1. Interaction effect on server sex influence

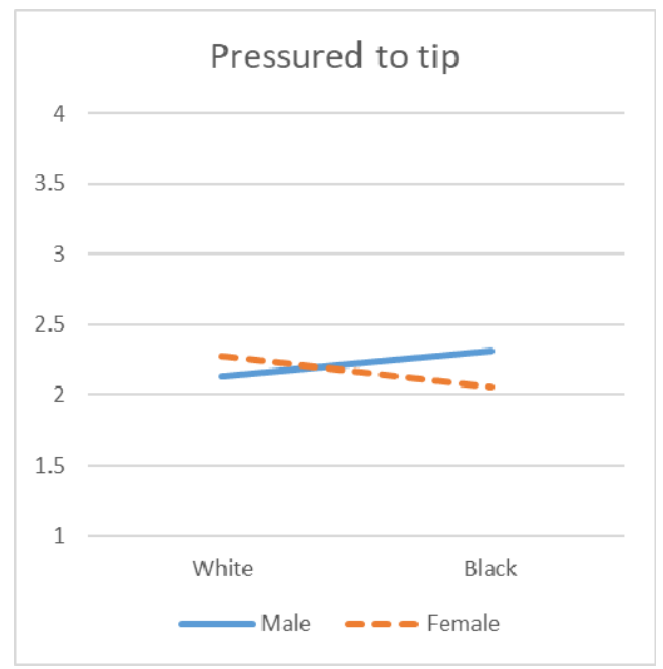

Figure 2. Interaction effect on tipping pressure 


\section{Discussion and Implications}

This study used an online consumer panel of 623 respondents to examine sex and race differences in consumer tipping behavior to further elucidate the main effects of personal and social norms on consumer tipping behavior. The findings demonstrated that these tipping norms differ between African-Americans and Whites, as well as men and women.

Restaurant servers work for tips, and it is still unclear how to motivate different races to tip them. If African-American men do not know about the tipping norms for poor, mediocre, or excellent service, then perhaps specific tip percentages should be notated on each restaurant's bill, the menu, and other marketing literature that restaurants provide their guests. While many restaurants include these percentages for their customers' reference, many do not. This finding is particularly important for all restaurants which employ servers to accommodate guests. Moreover, given that restaurant tips are not required in many establishments (other than with catering banquets and large groups), restaurants should make the expectation of tipping entirely clear to the guests. Also, restaurant managers must train all servers to interact with their guests continuously to gauge the rapport they establish with them. If African-American consumers do not enjoy their experience with one specific server, then it may be necessary to change servers or have another server check in during the experience, to heighten the rapport.

Additionally, the sex of the server was found to influence African-American males to tip; however, the finding is problematic in that restaurants may not have the ability to employ servers of only one or the other sex. Regarding the finding that African-American males feel a greater sense of obligation to tip, perhaps servers in restaurants that include a gratuity, on large parties, should inform the dining party at the beginning of the meal of such arrangements to make everyone comfortable by mitigating this feeling and making the guests comfortable. The finding supports earlier reports that the sex of the server plays a role in tipping (Kim, Nemeschansky, \& Brandt, 2017). Servers need to be cognizant that African-American males feel more obligated to tip when in a group setting, and thus, interacting with all members in the group is critical and proves strategically beneficial for servers.

Concerning the feeling of internal pressure to tip, African-American males and White females scored the highest. Servers must seek to make an authentic connection with these groups, and make them feel genuinely comfortable. When servers return the change or the credit card slip, they may offer additional service or move away from the guest to reduce the pressure on them. Further, managers may employ technological devices (e.g., handheld mobile POS devices) to give the guests further privacy, as tipping is a personal choice in an attempt to mitigate the feelings of conforming to the social norm. Finally, the findings of this study can be used for practical purposes, such as diversity training and diversity initiatives which focus on the equal treatment of clientele based on race and sex.

\section{Limitations and Future Research}

The study has several limitations that offer opportunities for future research. First, the literature includes no scale items of personal and social tipping norms. Therefore, we could not test the scale's validity; future research should focus on developing such scales to increase their validity. Second, the numbers of White and African-American respondents were uneven: 61\% Whites and 39\% African-Americans. Thus, future research should use more even sample sizes of these two racial groups. Third, African-Americans were the only racial or ethnic minority group included in our study. Future studies should expand their samples to include Hispanic- and Asian-Americans to test the ability to generalize our findings to other racial or ethnic groups. Finally, tipping norms can be examined cross-culturally to determine the way norms vary by culture. Nonetheless, we believe that personal and social restaurant tipping norms continue to evolve, and need continuous scrutiny. We hope that this study encourages other researchers to continue their interest in this subject.

\section{References}

Ayres, I., Vars, F. E., \& Zakariya, N. (2005). To insure prejudice: Racial disparities in taxicab tipping. Yale Law Journal, 114, 1613-1674.

Azar, O. H. (2004). What sustains social norms and how they evolve? The case of tipping. Journal of Economic Behavior \& Organization, 54(1), 49-64. https://doi.org/10.1016/j.jebo.2003.06.001

Azar, O. H. (2007a). The social norm of tipping: A review. Journal of Applied Social Psychology, 37(2), 380-402. https://doi.org/10.1111/j.0021-9029.2007.00165.x

Azar, O. H. (2007b). Why pay extra? Tipping and the importance of social norms and feelings in economic theory. The Journal of Socio-Economics, 36(2), 250-265. https://doi.org/10.1016/j.socec.2005.11.046 
Azar, O. H. (2010). Tipping motivations and behavior in the US and Israel. Journal of Applied Social Psychology, 40(2), 421-457. https://doi.org/10.1111/j.1559-1816.2009.00581.x

Banks, G. C., Woznyj, H. M., Kepes, S., Batchelor, J. H., \& McDaniel, M. A. (2018). A meta - analytic review of tipping compensation practices: An agency theory perspective. Personnel Psychology, 71(3), 457-478. https://doi.org/10.1111/peps. 12261

Baumeister, R. F., \& Sommer, K. L. (1997). What do men want? Gender differences and two spheres of belongingness: Comment on Cross and Madson. Psychological Bulletin, 122(July), 38-44. https://doi.org/10.1037/0033-2909.122.1.38

Berenguer, J. (2010). The effect of empathy in environmental moral reasoning. Environment and Behavior, 42(1), 110-134. https://doi.org/10.1177/0013916508325892

Brewster, Z. W., \& Lynn, M. (2014). Black-White earnings gap among restaurant servers: A replication, extension, and exploration of consumer racial discrimination in tipping. Sociological Inquiry, 84(4), 545-569. https://doi.org/10.1111/soin.12056

Brewster, Z., \& Mallinson, C. (2009). Racial differences in restaurant tipping: A labour process perspective. The Service Industries Journal, 29(8), 1053-1075. https://doi.org/10.1080/02642060902764343

Brewster, Z. W., \& Nowak III, G. R. (2018). Racial prejudices, racialized workplaces, and restaurant servers' hyperbolic perceptions of black-white tipping differences. Cornell Hospitality Quarterly, Cornell Hospitality Quarterly, 60(2), 159-173. https://doi.org/10.1177/1938965518777221

Conlin, M., Lynn, M., \& O’Donoghue, T. (2003). The norm of restaurant tipping. Journal of Economic Behavior \& Organization, 52(3), 297-321. https://doi.org/10.1016/S0167-2681(03)00030-1

Cross, S. F., \& Madson, L. (1997). Models of the self: Self-construals and gender. Psychological Bulletin, 122(July), 5-37. https://doi.org/10.1037/0033-2909.122.1.5

de Morais Sato, P., da Rocha Pereira, P., de Carvalho Stelmo, I., Unsain, R. F., Ulian, M. D., Sabatini, F., ... \& Scagliusi, F. B. (2014). Eating practices and habitus in mothers. A Brazilian population-based survey. Appetite, 82, 16-28. https://doi.org/10.1016/j.appet.2014.07.002

Dirks, D., \& Rice, S. K. (2004a). Dining while black: Racial rituals and the black American restaurant experience. In R. Coates (Ed.), Race and ethnicity - across time, space, and discipline (pp. 255-277). Leiden, The Netherlands: Brill Publishing.

Dirks, D., \& Rice, S. K. (2004b). Dining while black: Tipping as social artifact. Cornell Hotel and Restaurant Administration Quarterly, 45(1), 30-47. https://doi.org/10.1177/0010880403260105

Doran, R., \& Larsen, S. (2016). The relative importance of social and personal norms in explaining intentions to choose eco-friendly travel options. International Journal of Tourism Research, 18(2), 159-166. https://doi.org/10.1002/jtr.2042

Elster, J. (2007). Explaining social behavior: More nuts and bolts for the social sciences. Cambridge, New York: Cambridge University Press. https://doi.org/10.1017/CBO9780511806421

Fehr, E., \& Falk, A. (2002). Psychological foundations of incentives. European Economic Review, 46(4/5), 687-724. https://doi.org/10.1016/S0014-2921(01)00208-2

Grenfell, M. (2014). Pierre Bourdieu: Key concepts. Durham, NC: Routledge.

Han, H., Hwang, J., Lee, M. J., \& Kim, J. (2019). Word-of-mouth, buying, and sacrifice intentions for eco-cruises: Exploring the function of norm activation and value-attitude-behavior. Tourism Management, 70, 430-443. https://doi.org/10.1016/j.tourman.2018.09.006

Kallgren, C. A., Reno, R. R., \& Cialdini, R. B. (2000). A focus theory of normative conduct: When norms do and do not affect behavior. Personality and Social Psychology Bulletin, 26(8), 1002-1012. https://doi.org/10.1177/01461672002610009

Kim, C., \& Kim, S. H. (2019). Social image or social norm? Re-examining the audience effect in dictator game experiments. Journal of Behavioral and Experimental Economics, 79, 70-78. https://doi.org/10.1016/j.socec.2019.02.001

Kim, P. B., Nemeschansky, B., \& Brandt, L. (2017). An exploratory study of determinants for restaurant servers' actual tip earnings: Individual characteristics and work conditions. Journal of Foodservice Business Research, 20(1), 15-33. https://doi.org/10.1080/15378020.2016.1192883 
Koku, P. S. (2005). Is there a difference in tipping in restaurant versus non-restaurant service encounters, and do ethnicity and gender matter? Journal of Services Marketing, 19(7), 445-452. https://doi.org/10.1108/08876040510625954

Lee, H. E. (2015). Does a server's attentiveness matter? Understanding intercultural service encounters in restaurants. International Journal of Hospitality Management, 50, 134-144. https://doi.org/10.1016/j.ijhm.2015.08.003

Lynn, M. (2000). Servers' perceptions of who are good and poor tippers. Unpublished manuscript, School of Hotel Administration, Cornell University, Ithaca, NY.

Lynn, M. (2003). Restaurant tips and service quality: A weak relationship or just weak measurement. International Journal of Hospitality Management, 22(3), 321-325. https://doi.org/10.1016/S0278-4319(03)00048-3

Lynn, M. (2004a). Ethnic differences in tipping: A matter of familiarity with tipping norms. Cornell Hotel and Restaurant Administration Quarterly, 45(1), 12-22. https://doi.org/10.1177/0010880403260101

Lynn, M. (2004b). Black-white differences in tipping of various service providers. Journal of Applied Social Psychology, 34(11), 2261-2271. https://doi.org/10.1111/j.1559-1816.2004.tb01976.x

Lynn, M. (2006a). Race differences in restaurant tipping: A literature review and discussion of practical implications. Journal of Foodservice Business Research, 9, 99-113. https://doi.org/10.1300/J369v09n04_07

Lynn, M. (2006b). Tipping in restaurants and around the globe: An interdisciplinary review. In M. Altman (Ed.), Handbook of contemporary behavioral economics: Foundations and developments (pp. 626-643). Armonk, NY: ME Sharpe.

Lynn, M. (2009). Individual differences in self-attributed motives for tipping: Antecedents, consequences, and implications. International Journal of Hospitality Management, 28(3), 432-438. https://doi.org/10.1016/j.ijhm.2008.10.009

Lynn, M., \& Brewster, Z. (2015). Racial and ethnic differences in tipping: The role of perceived descriptive and injunctive tipping norms. Cornell Hospitality Quarterly, 56(1), 68-79. https://doi.org/10.1177/1938965514553466

Lynn, M., \& Grassman, A. (1990). Restaurant tipping: An examination of three rational explanations. Journal of Economic Psychology, 11, 169-181. https://doi.org/10.1016/0167-4870(90)90002-Q

Lynn, M., \& Sturman, M. (2010). Tipping and service quality: A within-subjects analysis. Journal of Hospitality \& Tourism Research, 34(2), 269-275. https://doi.org/10.1177/1096348009350637

Lynn, M., Sturman, M., Ganley, C., Adams, E., Douglas, M., \& McNeil, J. (2008). Consumer racial discrimination in tipping: A replication and extension. Journal of Applied Social Psychology, 38(4), 1045-1060. https://doi.org/10.1111/j.1559-1816.2008.00338.x

Lynn, M., \& Thomas-Haysbert, C. (2003). Ethnic differences in tipping: Evidence, explanations, and implications. Journal of Applied Social Psychology, 33, 1747-1772. https://doi.org/10.1111/j.1559-1816.2003.tb01973.x

Maynard, L. J., \& Mupandawana, M. (2009). Tipping behavior in Canadian restaurants. International Journal of Hospitality Management, 28(4), 597-603. https://doi.org/10.1016/j.ijhm.2009.03.011

Mestre, M., Sampler, P., Frias, M., \& Tur, A. (2009). Are women more empathetic than men? A longitudinal study in adolescence. The Spanish Journal of Psychology, 12(1), 76-83. https://doi.org/10.1017/S1138741600001499

Mulinari, P., Guest, D., \& Isaksson, K. (2019). Weapons of the poor: Tipping and resistance in precarious times. Economic and Industrial Democracy, 40(2), 434-451. https://doi.org/10.1177/0143831X16653188

Ndubisi, N. O. (2006). Effect of gender on customer loyalty: A relationship marketing approach. Marketing Intelligence \& Planning, 24(1), 48-61. https://doi.org/10.1108/02634500610641552

Parasuraman, A., Zeithaml, V., \& Berry, L. (1985). A conceptual model of service quality and its implications for future research. Journal of Marketing, 49(1), 41-50. https://doi.org/10.1177/002224298504900403

Parasuraman, A., Zeithaml, V., \& Berry, L. (1988). SERVQUAL: Multiple-item scale for measuring consumer perceptions of service quality. Journal of Retailing, 64(1), 12-40.

Parrett, M. (2006). An analysis of the determinants of tipping behavior: A laboratory experiment and evidence 
from restaurant tipping. Southern Economic Journal, 73(2), 489-514. https://doi.org/10.2307/20111903

Schram, A., \& Charness, G. (2015). Inducing social norms in laboratory allocation choices. Management Science, 61, 1531-1546. https://doi.org/10.1287/mnsc.2014.2073

Schwer, R. K., \& Daneshvary, R. (2000). Keeping up one's appearance: Its importance and the choice of type of hair-grooming establishment. Journal of Economic Psychology, 21(2), 207-222. https://doi.org/10.1016/S0167-4870(99)00043-4

Stephen, R., \& Zweigenhaft, R. L. (1986). The effect on tipping of a waitress touching male and female customers. The Journal of Social Psychology, 126(1), 141-142. https://doi.org/10.1080/00224545.1986.9713586

Teng, C. C., \& Chang, J. H. (2013). Mechanism of customer value in restaurant consumption: Employee hospitality and entertainment cues as boundary conditions. International Journal of Hospitality Management, 32, 169-178. https://doi.org/10.1016/j.jhm.2012.05.008

Trivedi, R. H., \& Teichert, T. (2019). The effect of ad smiles on consumer attitudes and intentions: Influence of model gender and consumer gender. Journal of Business Research, 99, 197-205. https://doi.org/10.1016/j.jbusres.2019.02.052

Whaley, J. E. (2011). What's in a tip? An exploratory study of the motivations driving consumer tipping behavior. (Ph.D. 3480658), Auburn University, United States-Alabama. Retrieved from http://argo.library.okstate.edu/login?url=http://search.proquest.com/docview/900314159?accountid=4117 ProQuest Dissertations \& Theses (PQDT) database.

Whaley, J. E., Douglas, A. C., \& O'Neill, M. A. (2014). What's in a tip? The creation and refinement of a restaurant tipping motivations scale: A consumer perspective. International Journal of Hospitality Management, 37(0), 121-130. https://doi.org/10.1016/j.ijhm.2013.11.005

Whaley, J. E., Kim, S. H., \& Kim, Y. K. (2019). Drivers and impact of restaurant tipping behavior. Journal of Foodservice Business Research, 22(2), 117-131. https://doi.org/10.1080/15378020.2019.1570773

Whaley, J. E., Lee, J., \& Kim, Y-K. (2019). Do tipping motivations lead to server loyalty in a restaurant? International Hospitality Review. https://doi.org/10.1108/IHR-01-2019-0001

\section{Copyrights}

Copyright for this article is retained by the author, with first publication rights granted to the journal.

This is an open-access article distributed under the terms and conditions of the Creative Commons Attribution license (http://creativecommons.org/licenses/by/4.0/). 